\section{Investigation of Eye Lens Dose Estimate based on AAPM Report 293 in Head Computed Tomography}

\author{
Choirul Anam*๑, Winda Kusuma Dewi², Masdi Masdi³, \\ Freddy Haryanto ${ }^{4}$, Toshioh Fujibuchi' ${ }^{5}$, Geoff Dougherty ${ }^{6}$
}

\begin{abstract}
Background: Estimation of eye lens dose is important in head computed tomography $(\mathrm{CT})$ examination since the eye lens is a sensitive organ to ionizing radiation.

Objective: The purpose of this study is to compare estimations of eye lens dose in head CT examinations using local size-specific dose estimate (SSDE) based on size-conversion factors of the American Association of Physicists in Medicine (AAPM) Report No. 293 with those based on size-conversion factors of the AAPM Report No. 220.

Material and Methods: This experimental study is conducted on a group of patients who had undergone nasopharyngeal CT examination. Due to the longitudinal ( $z$-axis) dose fluctuation, the average global SSDE and average local SSDE (i.e. particular slices where the eyes are located) were investigated. All estimates were compared to the measurement results using thermo-luminescent dosimeters (TLDs). The estimated and measured doses were implemented for 14 patients undergoing nasopharyngeal CT examination.
\end{abstract}

Results: It was found that the percentage differences of the volume CT dose index $\left(\mathrm{CTDI}_{\mathrm{vol}}\right)$, average global SSDE based on AAPM No. 220 (SSDE ${ }_{\mathrm{o}, \mathrm{g}}$ ), average local SSDE based on AAPM No. $220\left(\mathrm{SSDE}_{\mathrm{o}, 1}\right)$, average global SSDE based on AAPM No. $293\left(\mathrm{SSDE}_{\mathrm{n}, \mathrm{g}}\right)$ and average local SSDE based on AAPM No. 293 $\left(\mathrm{SSDE}_{\mathrm{n}, \mathrm{l}}\right)$ against the measured TLD doses were 22.5, 21.7, 15.0, 9.3, and 2.1\%, respectively. All comparisons between dose estimates and TLD measurements gave $p$-values less than 0.001, except for $\operatorname{SSDE}_{\mathrm{n}, 1}$ ( $p$-value $=0.566$ ).

Conclusion: SSDE based on AAPM Report No. 293 can be used to accurately estimate eye lens radiation doses by performing the calculations on a number of specific slices containing the eyes.

Citation: Anam Ch, Dewi WK, Masdi M, Haryanto F, Fujibuchi T, Dougherty G. Investigation of Eye Lens Dose Estimate based on AAPM Report 293 in Head Computed Tomography. J Biomed Phys Eng. 2021;11(5):563-572. doi: 10.31661/jbpe.v0i0.2104-1304

\section{Keywords}

Radiation; lonizing; X-Rays; Computed Tomography; Algorithms; Eye Lens Dose; Organ Dose; Size-Specific Dose Estimates

\section{Introduction}

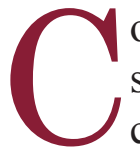
omputed tomography (CT) scanners have long been used to stage and assess patients suspected of having nasopharyngeal carcinoma (NPC) $[1,2]$. The NPC detection is usually followed by injection of contrast agent to enhance differentiation among surrounding tissues to facilitate the evaluation of the lesions [3]. The NPC
${ }^{1} \mathrm{PhD}$, Department of Physics, Faculty of Sciences and Mathematics, Diponegoro University, Jl. Prof. Soedarto SH, Semarang 50275, Central Java, Indonesia

${ }^{2} \mathrm{MSc}$, Department of

Physics, Faculty of Sci-

ences and Mathematics,

Diponegoro University,

Jl. Prof. Soedarto SH, Semarang 50275, Central

Java, Indonesia

${ }^{3} \mathrm{BSc}$, Department of

Radiology, Prof. Margono

Hospital, Purwokerto,

Indonesia

${ }^{4} \mathrm{PhD}$, Department of

Physics, Faculty of Mathematics and Natural Sciences, Institut Teknologi Bandung Jl. Ganesha

10 Bandung 40132,

Indonesia

${ }^{5} \mathrm{PhD}$, Department of

Health Sciences, Faculty

of Medical Sciences,

Kyushu University, 3-1-1

Maidashi, Higashi-ku,

Fukuoka 812-8582,

Japan

${ }^{6} \mathrm{PhD}$, Department of Applied Physics and Medi-

cal Imaging, California

State University Channel

Islands, Camarillo, CA

93012, USA

*Corresponding author: Choirul Anam

Department of Physics,

Faculty of Sciences and

Mathematics, Dipon-

egoro University, J. Prof.

Soedarto SH, Semarang

50275, Central Java,

Indonesia

E-mail: anam@fisika.

fsm.undip.ac.id

Received: 9 April 2021

Accepted: 22 June 2021 
examination combined with contrast agents necessitates the scanning to be conducted twice, i.e. pre- and post-contrast agent injections. As a result, the radiation dose accumulated to the patient is higher than a general head CT examination, resulting in a concern particularly for the eye lens considered to be a high radiosensitive tissue. A recent study highlighted the risk of lens opacity as a potential consequence related to exposure, even for low doses of ionizing radiation [4]. Others have reported radiation-induced cataract formation $[5,6]$. In order to assess the radiation risks, accurate estimates of the doses deposited in the eye lens of exposed individuals under the NPC examinations are urgently required.

Experimental eye lens dose measurements are often carried out using an anthropomorphic phantom and small detectors, i.e. thermoluminescent dosimeters (TLDs) [7, 8], metaloxide-semiconductor field-effect transistors (MOSFET) [9], or optically stimulated luminescent (OSL) dosimeters [10, 11]. A computational approach can be carried out through Monte Carlo (MC) simulations using a voxel phantom $[8,12,13]$ to represent a wide range of sizes [14]. MC simulations provide a closer estimation of organ dose to a patient, but it is computationally time-consuming and requires highly specialized skill intervention to simulate a voxel model [8]. An alternative is to make the use of pre-computed organ doses from MC computational phantom libraries, but several of the existing $\mathrm{CT}$ organ dose estimation tools are considered to be out-ofdate and not entirely representative of human anatomy [15].

The dose descriptor, directly accessible at the scanning, is the volume of computed tomography dose index $\left(\mathrm{CTDI}_{\mathrm{vol}}\right)$. Studies have been conducted to correlate the CTDI${ }_{\text {vol }}$ displayed on the CT console and the eye lens dose among patients [16-18]. Zhang et al. [16] reported that the ratio of eye lens dose to $\mathrm{CTDI}_{\mathrm{vol}}$ was 59 - 63\%. More recently, Lopez-Rendon et al. [8] reported that CTDI $_{\text {vol }}$ overestimated the eye lens dose by up to $41 \%$. Suzuki et al. [17] reported that the ratio of eye lens doses to CTDI ${ }_{\text {vol }}$ fell in a range of $81-103 \%$, showing that $\mathrm{CTDI}_{\mathrm{vol}}$ can only be applied to estimate the eye lens dose in a specific clinical setting. In fact, CT$\mathrm{DI}_{\mathrm{vol}}$ provides the fundamental output radiation dose for scanners, but has limitations for estimating patient dose due to the absence of patient size in its framework [18].

For the purpose of estimating absorbed dose in patients, the American Association of Physicists in Medicine (AAPM) developed the size-specific dose estimate, SSDE (Report No. 204, 2011). The SSDE takes into consideration the CTDI ${ }_{\mathrm{vol}}$ and a conversion factor $(f)$ describing the patient size in terms of an effective diameter $\left(\mathrm{D}_{\text {eff }}\right)$ [19]. In 2014, AAPM improved the SSDE concept in Report No. 220 and introduced the water-equivalent diameter $\left(D_{w}\right)$, which took into account the geometrical size and patient attenuation [20]. The $\mathrm{D}_{\mathrm{w}}$ metric had previously been proposed by Wang et al. [21] and was subsequently adopted as the gold standard in representing radiological patient size for dose estimation. However, the size-conversion factors tabulated in AAPM Reports No. 204 and No. 220 were specifically modeled in the abdominal-pelvic region. Therefore, in 2019 AAPM renewed the size-conversion factor for the head region in Report No. 293, taking into account that the dose accumulated in the brain is significantly different from the doses absorbed in other parts of the body [22].

The SSDE metric may be a practical approach for estimating organ dose [18]. Several groups have explored the potential correlation between SSDE and organ doses [23-25]. The radial dose distributions at the center and the periphery of the patient may not be uniform, particularly in the body region [18]. However, the dose distribution in the center 
Eye Lens Dose Estimate Based on AAPM 293

of a $16 \mathrm{~cm}$ PMMA phantom was reported to be similar to the dose at the periphery [26]. In another study, Anam et al. [27] explored various physical sizes of acrylic phantoms within a range of $8-32 \mathrm{~cm}$ and reported that $\mathrm{D}_{\mathrm{w}}$ within a range of $12-14 \mathrm{~cm}$ had a homogeneous dose distribution for both central and peripheral regions. Therefore, the SSDE may be useful for organ dose estimation within the head region without any consideration of fluctuations in the radial dose distribution. Another uncertainty in estimating the organ dose from SSDE is the dose distribution along the $z$-axis. An accurate organ dose estimation needs to consider the $z$-axis distribution by employing local SSDE at particular $z$-axis values [25]. This is because the SSDE is strongly dependent on fluctuations of $\mathrm{D}_{w}$ along the $z$-axis.

The concept of SSDE to estimate the eye lens dose of patients, undergoing nasopharyngeal CT examinations by taking the specific $z$-axis values within the eye region (according to AAPM Report No. 220), was investigated by Anam et al. [28]. The estimated doses were then compared to the measured doses from TLDs. The results showed that that approach provided a closer match to the measured radiation dose than the average of the global SSDE, although the discrepancy from the TLD measurement was still more than $10 \%$ [28]. With the update of the sizeconversion factor provided by AAPM Report No. 293, the SSDE may estimate the organ dose more accurately. This study aims to investigate the eye lens dose by implementation of the local SSDE in $z$-axis specific regions of patients undergoing nasopharyngeal CT examination using the AAPM Report No. 293 size-conversion factors.

\section{Material and Methods}

\section{Patient preparation}

This experimental study was conducted with a group of patients, who had undergone nasopharyngeal CT examination at Prof. Dr. Margono Soekarjo Hospital, Purwokerto, Central Java, Indonesia. A total of fourteen patients (3 male and 11 female), ranging from 21 to 72 years old were included in this study. Eight patients were assigned to contiguous axial mode and the other six patients were examined in helical mode. All scans were performed with a Somatom Emotion 6 CT scanner (Siemens AG, Forchheim, Germany), operating at $120 \mathrm{kVp}$ and $250 \mathrm{mAs}$. The examinations obtained anatomical images along the vertex to skull base with a total of 29 - 34 slices with thickness of each is $4 \mathrm{~mm}$ and reconstruction diameter of $200 \mathrm{~mm}$.

\section{Eye lens radiation dose measure- ment}

The high sensitive TLD-100 chips (Harshaw Chemical Company, Solon, Ohio, USA) with dimension of $3.175 \times 3.175 \times 0.889 \mathrm{~m}^{3}$ were used for measuring the eye lens radiation dose. The TLD-100 contains $92.5 \%{ }^{7} \mathrm{Li}$ plus $7.5 \%{ }^{6} \mathrm{Li}$ and impurities, including magnesium and titanium to increase electron traps and sensitivity. Effective atomic number of the TLD-100 is nearly similar to those of the body tissues. For simplicity, the TLD-100 is written in the current report as TLD. The calibration of the TLDs was performed at Department of Dosimetry, Center of Safety Technology and Radiation Metrology, National Nuclear Energy Agency (PTKMR-BATAN) as the secondary standard dosimetry laboratory (SSDL) in Indonesia. The annealing cycle consisted of a heating phase $\left(400{ }^{\circ} \mathrm{C}\right.$ for 1 hour in a furnace, $200{ }^{\circ} \mathrm{C}$ for 2 hours in an oven). The TLDs were then cooled down until equilibrated to room temperature and packed into plastic bags each containing three TLDs chips. The TLDs were positioned on the eye surfaces and read by a TLD reader of 2000 A/B (Harshaw, Chemical Company, Solon, Ohio, USA) after irradiation. Accurate measurement of the eye lens dose required to put $5 \mathrm{~mm}$ of tissue equivalent on TLD chips. 
However, measurements in the current study were conducted without additional $5 \mathrm{~mm}$ of tissue equivalent, hence the dose obtained was the entrance surface dose (ESD) of eye lens rather than the eye lens dose. In the current study, the term of the eye lens dose was used as an approximation of the ESD of eye lens. The final estimate of the eye lens dose was taken as the average dose from the three TLDs within a bag multiplied by the corresponding calibration factor. The measured dose from the TLDs was used as a reference for dose assessment.

\section{Calculation of $\mathrm{D}_{w}$}

In this study, the patient size was determined using the attenuation-based size metric $\left(D_{w}\right)$ calculated from the patient image. To determine the value of $\mathrm{D}_{\mathrm{w}}$, a derivative formula from AAPM Report No. 220 was adopted:

$$
D_{w}=2 \sqrt{\left[\frac{1}{1000} \overline{C T(x, y)}+1\right]} \frac{A}{\pi}
$$

where $A$ is the patient area for every slice and $\overline{C T(x, y)}$ is the average value of $\mathrm{CT}$ number inside the patient area, expressed in
Hounsfield units (HU). An automated method was used to obtain the $\mathrm{D}_{\mathrm{w}}$ value [29]. Using Equation (1), the average of the global $\mathrm{D}_{\mathrm{w}}$ $\left(D_{w, g}\right)$ and the average of the local $D_{w}\left(D_{w, 1}\right)$ values characterize the dose measurement of eye organs for each patient. $\mathrm{D}_{\mathrm{w}, \mathrm{g}}$ is the average value of total $\mathrm{D}_{\mathrm{w}}$ from the $\mathrm{N}$ slices along the scan axis.

$$
D_{w, g}=\frac{\sum_{i=1}^{N} D w_{i}}{N}
$$

$\mathrm{D}_{\mathrm{w}, 1}$ is the average value of local $\mathrm{D}_{\mathrm{w}}$ calculated using a certain number of slices $(n)$, containing the eye's field of view. To determine the value of $\mathrm{D}_{\mathrm{w}, \mathrm{l}}$, the position of the eye organs along the $z$-axis is manually observed and defined by the user. Then the diameter was calculated using Equation (1) and divided by the number of slices $(n)$ where the eye organs are located to give $\mathrm{D}_{\mathrm{w}, 1}$ (Equation (3)). The determination of the value of $D_{w, g}$ and $\mathrm{D}_{\mathrm{w}, 1}$ is illustrated in Figure 1.

$$
D_{w, l}=\frac{\sum_{i=1}^{n} D w_{i}}{n}
$$

\section{Dose Calculations}

The calculated values of global $\mathrm{D}_{\mathrm{w}}$ and local $\mathrm{D}_{\mathrm{w}}$ were then used to estimate the SSDE val-

(b)

\section{(a)}

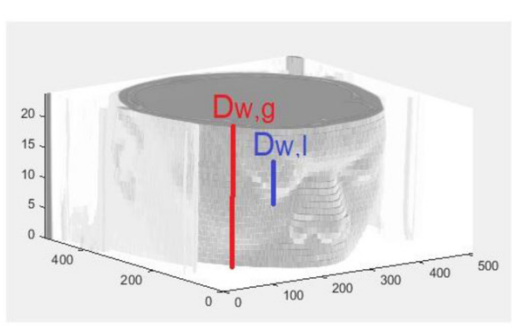

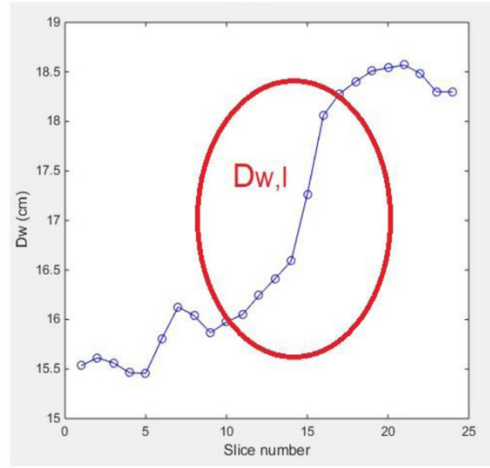

Figure 1: $D_{w, g}$ represents the average value of total $D_{w}$ at the start to the end of scanning along the $z$-axis, while $D_{w, l}$ is the average of local $D_{w}$ is calculated only from the image of the eye's field of view that (a) illustrates the positions taken in calculating $D_{w, g}$ and $D_{w, l}$, and (b) shows the $D_{w}$ profiles from the $1^{\text {st }}$ slice to the $24^{\text {th }}$ slice. In this case, $D_{w, I}$ is calculated as the average of local $D_{w}$ from the $11^{\text {th }}$ to $17^{\text {th }}$ slices $(n=6)$. 
Eye Lens Dose Estimate Based on AAPM 293

ue for each slice. SSDE formula was shown in Equation (4). The dose estimation in this current study used the size-conversion factor of AAPM Report No. $293\left(f_{n}\right)$, and a CTDI $_{\text {vol }}$ value recorded from the CT scan console screen, rather than the conversion factors $\left(f_{o}\right)$ from AAPM Report No. 220 used in the previous study. The $\mathrm{D}_{\mathrm{w}}$ and SSDE were calculated using the IndoseCT 20b software [30]. Plots of the size-conversion factors $\left(f_{o}\right.$ and $f_{n}$ ) versus $\mathrm{D}_{\mathrm{w}}$ are shown in Figure 2.

The SSDE can be estimated by two approaches, i.e. the average of global SSDE $\left(\operatorname{SSDE}_{\mathrm{n}, \mathrm{g}}\right)$ showing the estimated dose values across all the slices during the examination, and the average of local SSDE $\left(\mathrm{SSDE}_{\mathrm{n}, \mathrm{l}}\right)$ represents the approximate dose at the slices where the eye organs are located. Both were shown in Equations (5) and (6), respectively. For comparison, the estimated doses calculated based on CTDI $_{\text {vol }}$ and the AAPM Report No. 220 conversion factor $\left(\mathrm{SSDE}_{\mathrm{ogg}}\right.$ and $\left.\mathrm{SSDE}_{\mathrm{o}, \mathrm{l}}\right)$ were calculated.

$$
\begin{aligned}
& S S D E=C T D I_{v o l} x f_{(\text {size })} \\
& S S D E_{g}=\frac{\sum_{i=1}^{N} S S D E_{i}}{N}
\end{aligned}
$$

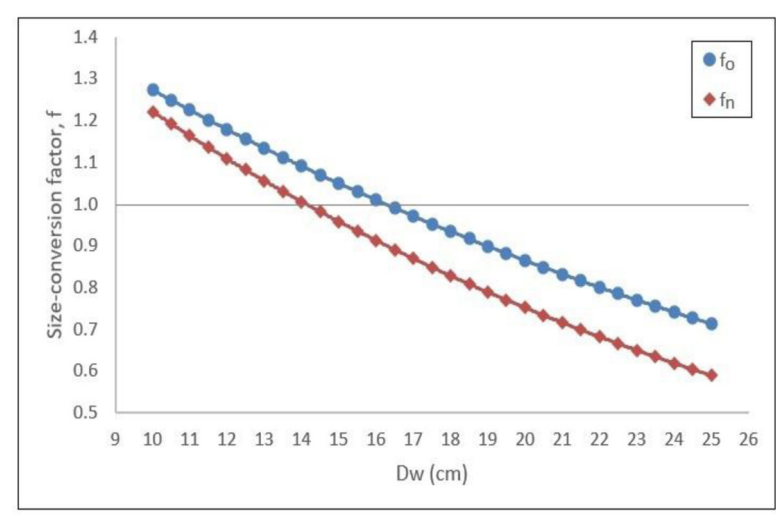

Figure 2: Size-conversion factors obtained from the American Association of Physicists in Medicine (AAPM) Report No. $293\left(f_{n}\right)$ and AAPM Report No. $220\left(f_{o}\right)$. For the same $D_{w^{\prime}}$ $f_{n}$ has a smaller value than $f_{o}$, so that the estimated doses using $f_{n}$ will be less than the estimated doses using $f_{0}$.

$$
S S D E_{l}=\frac{\sum_{i=1}^{n} S S D E_{i}}{n}
$$

\section{Statistical analysis}

A comparison of doses indicators, i.e. $\mathrm{CTDI}_{\mathrm{vol}}, \mathrm{SSDE}_{\mathrm{o}, \mathrm{g}}, \mathrm{SSDE}_{\mathrm{o}, \mathrm{l}}, \mathrm{SSDE}_{\mathrm{n}, \mathrm{g}}$, and $\mathrm{SSDE}_{\mathrm{n}, 1}$ against the measured doses of TLDs was obtained, along with the average and standard deviation values of their percentage differences. A statistical test using Wilcoxon Mann-Witney $U$ test at a significance level of 0.05 was performed to find if there is a statistically significant difference. All statistical analysis was conducted using the Matlab software (Mathworks Inc., Natick, Massachusetts, USA).

\section{Results}

Values of $D_{w, g}$ and $D_{w, 1}$

$\mathrm{D}_{\mathrm{w}, \mathrm{g}}$ (indicated by circular markers) and $\mathrm{D}_{\mathrm{w}, \mathrm{l}}$ (indicated by diamond markers) showed a similar trend (Figure 3a). The values of $\mathrm{D}_{\mathrm{w}, \mathrm{g}}$ $(16.41 \pm 1.04 \mathrm{~cm})$ were smaller than the values of $\mathrm{D}_{\mathrm{w}, 1}(17.82 \pm 0.79 \mathrm{~cm})$ for all patients included in this study. The relationship between them shows a statistically significant difference $(p$-value $=0.001)$.

\section{Comparisons of eye dose estima- tions against TLDs}

The measured doses using TLDs were used as the gold standard in this current study. The comparisons of the $\mathrm{CTDI}_{\mathrm{vol}}, \mathrm{SSDE}_{\mathrm{o}, \mathrm{g}}, \mathrm{SSDE}_{\mathrm{o}, \mathrm{l}}$, $\mathrm{SSDE}_{\mathrm{n}, \mathrm{g}}$, and $\mathrm{SSDE}_{\mathrm{n}, 1}$ against TLDs doses are presented in Figure 4 and Table 1. As expected, the CTDI ${ }_{\text {vol }}$ value was constant for each patient. The four estimated doses in terms of SSDE had a similar trend as the TLDs dose, but the ones that come closest to the measurement results were $\mathrm{SSDE}_{\mathrm{n}, 1}$ (percentage difference of $2.1 \pm 4.2 \%)$, followed by $\operatorname{SSDE}_{\mathrm{n}, \mathrm{g}}(9.3$ $\pm 4.3 \%), \mathrm{SSDE}_{\mathrm{o}, \mathrm{l}}(15.0 \pm 5.7 \%)$, and $\mathrm{SSDE}_{\mathrm{o}, \mathrm{g}}$ $(21.7 \pm 5.3 \%)$. Statistical analysis indicates that there was no significant difference be- 

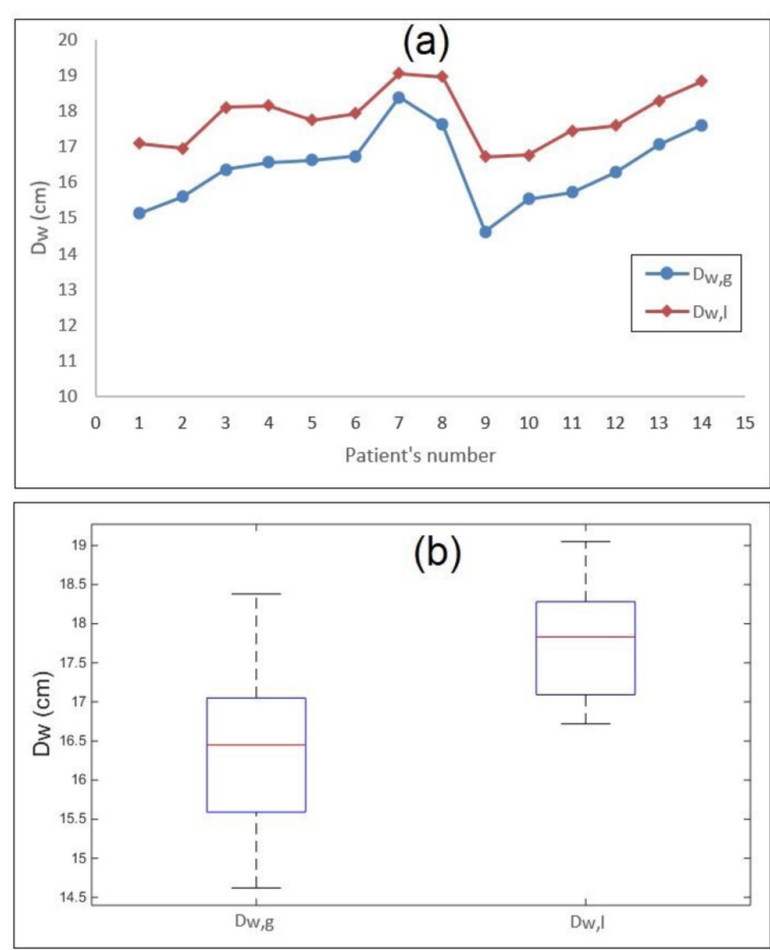

Figure 3: (a) The values of $D_{w, g}$ and $D_{w, 1}$ for all 14 patients, and (b) box-plot diagram indicates the distribution (the median, maximum, minimum, and interquartile range) of patient size in terms of $D_{w, g}$ and $D_{w, l^{\circ}}$. The $D_{w, 1}$ gives greater values than the $D_{w, g}(p$-value $=$ 0.0012).

tween TLDs doses and $\mathrm{SSDE}_{\mathrm{n}, 1}$.

\section{Discussion}

It has been reported that the radial distribution of dose in a head CT examination is homogeneous [26], so that the SSDE, which is an average dose within a patient, can be used to estimate the dose even in the organs at the edge of the head such as the eye. However, the diameter of the head of every patient fluctuates along the $z$-axis, and an accurate estimate of organ dose should consider this fluctuation. The SSDE along the $z$-axis depends on $\mathrm{D}_{\mathrm{w}}$ in fixed tube current (FTC) and depends on both $\mathrm{D}_{\mathrm{w}}$ and tube current in tube current modulation (TCM) [27].

A previous study [28] reported estimated
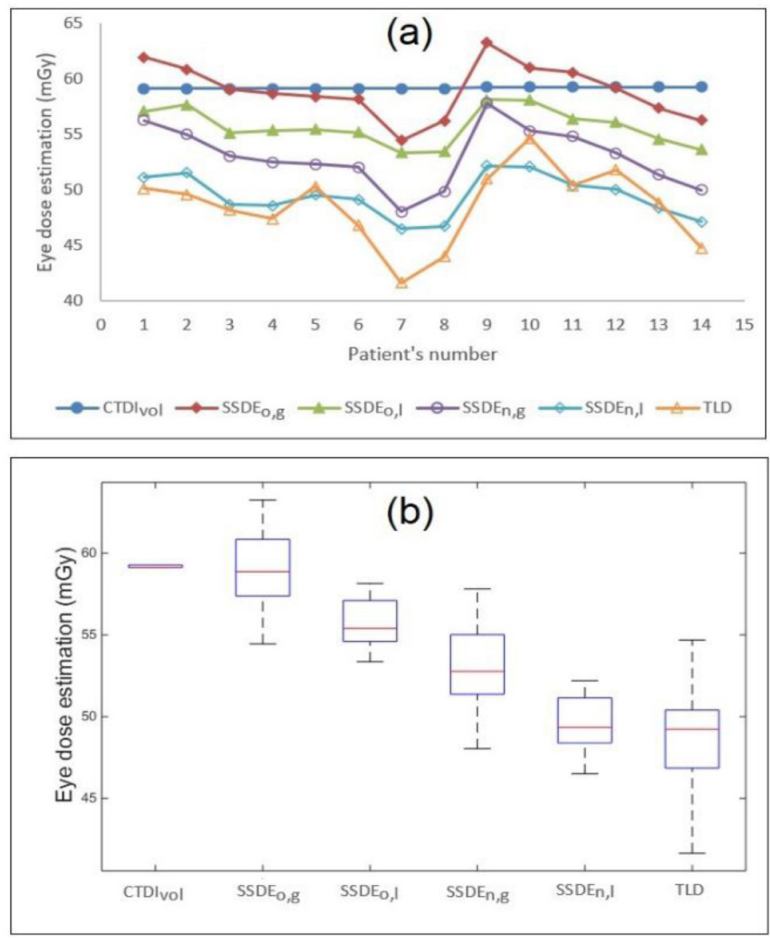

Figure 4: (a) Estimated eye lens doses radiation (CTDI $_{\text {vol' }}$ volume computed tomography dose index, $\mathrm{SSDE}_{\mathrm{n}, \mathrm{g}}$ average of global sizespecific dose estimate based on new report of the American Association of Physicists in Medicine (AAPM) No. 293, SSDE ${ }_{0, g^{\prime}}$ average of global size-specific dose estimate based on previously report of the AAPM No. 220, $\mathrm{SSDE}_{n, 1}$ : average of local size-specific dose estimate based on new report of AAPM No. 293, SSDE $_{0,1}$ : average of local size-specific dose estimate based on report of the AAPM No. 220) and measured doses using the thermo-luminescent dosimeters (TLDs), and (b) the dose distributions of the six descriptors in a box-plot diagram. $\mathrm{SSDE}_{n, 1}$ gave a more closely match estimation of eye lens doses to the measured doses.

eye lens doses by calculating the average of the global SSDE $\left(\mathrm{SSDE}_{\mathrm{o}, \mathrm{g}}\right)$ and the average of the local SSDE $\left(\mathrm{SSDE}_{\mathrm{o}, 1}\right)$ using AAPM Report No. 220 (16 cm CTDI phantom). The results showed that $\mathrm{SSDE}_{\mathrm{o}, 1}$ was closer than $\mathrm{SSDE}_{\mathrm{o}, \mathrm{g}}$ to the results measured using TLDs. The discrepancies between the $\mathrm{SSDE}_{\mathrm{o}, 1}$ results and 
Table 1: Percentage differences and $p$-values of eye radiation dose between the average of local size specific dose estimate (SSDE), average global SSDE, and volume computed tomography dose index $\left(\mathrm{CTDI}_{\text {vol }}\right)$ and the measured doses by the thermo-luminescent dosimeters (TLDs).

\begin{tabular}{ccc} 
Metrics & Percentage differences (\%) & $\boldsymbol{p}$-values \\
\hline CTDI $_{\text {vol }}$ & $22.5 \pm 8.9$ & $<0.001$ \\
\hline SSDE $_{0, \mathrm{~g}}$ & $21.7 \pm 5.3$ & $<0.001$ \\
\hline SSDE $_{0, \mathrm{I}}$ & $15.0 \pm 5.7$ & $<0.001$ \\
\hline SSDE $_{\mathrm{n}, \mathrm{g}}$ & $9.3 \pm 4.3$ & 0.001 \\
\hline SSDE $_{\mathrm{n} . \mathrm{I}}$ & $2.1 \pm 4.2$ & $0.566(>0.05)$
\end{tabular}

$\mathrm{CTDI}_{\mathrm{vol}}$ : Computed tomography dose index; $\mathrm{SSDE}_{\mathrm{n}, \mathrm{g}}$ : Average of global size-specific dose estimate based on new report of the American Association of Physicists in Medicine (AAPPM) No. 293; SSDE : Average of global size-specific dose estimate based on previously report of the AAPM No. 220; $\mathrm{SSDE}_{\mathrm{n}, 1}$ : Average of local size-specific dose estimate based on new report of AAPM No. 293; $\mathrm{SSDE}_{\mathrm{o}, 1}$ : Average of local size-specific dose estimate based on report of the AAPM No. 220.

the TLD measurements were about $16 \%$ [28]. However, size-conversion factors provided in that report were specifically intended for the abdominal-pelvic region. In this current study, we calculated the average of global and local SSDEs (denoted as $\operatorname{SSDE}_{\mathrm{n}, \mathrm{g}}$ and $\mathrm{SSDE}_{\mathrm{n}, \mathrm{l}}$ ) using $f_{n}$, the size-conversion factors for head CT examinations reported in AAPM Report No. 293.

The distributions of the six doses indicators observed in the current study are shown in Figure 4. The measured doses from calibrated TLDs were assigned as the gold standard. All patients had a CTDI vol value greater than the TLD doses by $22.5 \pm 8.9 \%$ that is consistent with the results reported by previous investigators $[8,16]$. There was a statistically significant difference between CTDI ${ }_{\text {vol }}$ and TLDs doses ( $p$-value $<0.001)$. The value of CTDI was constant for all patients, independent of patient size, so that it only characterizes the output radiation dose from a scanner [31]. This is indicative of fixed tube current (TCM) scans.

We then calculated the SSDE in terms of $\mathrm{SSDE}_{\mathrm{o}, \mathrm{g}}$ and $\mathrm{SSDE}_{\mathrm{o}, \mathrm{l}}$. Similar trends to the TLD doses were obtained, but the percentage differences in both cases were relatively high $\left(\mathrm{SSDE}_{\mathrm{o}, \mathrm{g}}=21.7 \pm 5.3 \%\right.$ and $\mathrm{SSDE}_{\mathrm{o}, 1}=15.0$ $\pm 5.7 \%$ ). A statistically significant difference was also observed from the resulting $p$-value $<0.001$. We then determined the values of $\mathrm{SSDE}_{\mathrm{n}, \mathrm{g}}$ and $\mathrm{SSDE}_{\mathrm{n}, \mathrm{l}}$. These metrics provided the closest estimated doses to the TLD measurements, viz. $\operatorname{SSDE}_{\mathrm{n}, 1}(2.1 \pm 4.2 \%)$ rather than $\operatorname{SSDE}_{\mathrm{n}, \mathrm{g}}(9.3 \pm 4.3 \%) . \mathrm{SSDE}_{\mathrm{n}, \mathrm{l}}$ did not show a statistically significant difference from the TLD doses ( $p$-value $=0.566)$.

An accurate eye dose estimation in patients suspected of NPC is very important. One of the main treatments for patients with NPC is high-dose radiotherapy, and the eye is one of organs at risk. Therefore, calculating the dose received by the eye in the diagnostic stages (diagnostic CT scan and/or CT simulation) and adding it to the dose received in radiation therapy will cause a more accurate calculation of the total dose of the eye.

This current study employed a very limited number of patients. Although it provides proof of concept. A further study with a larger cohort will be needed. Although the current study is only focused on eye lens dose, other organ doses within the head region can be treated similarly using the proposed approach since the radial dose within the head region is relatively homogeneous [28]. Estimates of organ doses outside the head would require 
the appropriate radial dose distribution within patient [26].

\section{Conclusion}

We estimated the eye lens dose using the average local SSDE within the eye location based on the size-conversion factors of AAPM Report No. $293\left(\mathrm{SSDE}_{\mathrm{n}, \mathrm{l}}\right)$. We compared these estimates with other metrics such as CTDI ${ }_{\text {vol }}$, $\mathrm{SSDE}_{\mathrm{o}, \mathrm{g}}, \mathrm{SSDE}_{\mathrm{o}, 1}$, and $\mathrm{SSDE}_{\mathrm{n}, \mathrm{g}}$. All the estimates were compared to measurements using TLDs. The differences from the TLDs were $22.5,21.7,15.0,9.3$, and $2.1 \%$ for $\mathrm{CTDI}_{\mathrm{vol}}$, $\mathrm{SSDE}_{\mathrm{o}, \mathrm{g}}, \mathrm{SSDE}_{\mathrm{o}, \mathrm{l}}$, and $\mathrm{SSDE}_{\mathrm{n}, \mathrm{g}}$, respectively. Thus, the average of local SSDE calculated using size-conversion factors of AAPM Report No. 293 gives the highest accuracy for estimating eye lens radiation doses.

\section{Acknowledgment}

This work was funded by the World Class Research University (WCRU), Diponegoro University, No. 118-08/UN7.6.1/PP/2021.

\section{Conflict of Interest}

None

\section{References}

1. Razek AA, King A. MRI and CT of nasopharyngeal carcinoma. AJR Am J Roentgenol. 2012;198(1):11-8. doi: 10.2214/AJR.11.6954. PubMed PMID: 22194474.

2. Manavis J, Sivridis L, Koukourakis MI. Nasopharyngeal carcinoma: the impact of CT-scan and of MRI on staging, radiotherapy treatment planning, and outcome of the disease. Clin Imaging. 2005;29(2):128-33. doi: 10.1016/j.clinimag.2004.04.004. PubMed PMID: 15752969.

3. Lusic H, Grinstaff MW. X-ray-computed tomography contrast agents. Chem Rev. 2013;113(3):1641-66. doi: 10.1021/ cr200358s. PubMed PMID: 23210836. PubMed PMCID: PMC3878741.

4. Rajabi AB, Noohi F, Hashemi $H$, Haghjoo M, et al. Ionizing radiation-induced cataract in interventional cardiology staff. Res Cardiovasc Med. 2015;4(1):e25148. doi: 10.5812/cardio- vascmed.25148. PubMed PMID: 25789258. PubMed PMCID: PMC4350158.

5. Chodick G, Bekiroglu N, Hauptmann M, Alexander $\mathrm{BH}$, et al. Risk of cataract after exposure to low doses of ionizing radiation: a 20-year prospective cohort study among US radiologic technologists. Am J Epidemiol. 2008;168(6):620-31. doi: 10.1093/aje/ kwn171. PubMed PMID: 18664497. PubMed PMCID: PMC2727195.

6. Yuan MK, Tsai DC, Chang SC, Yuan MC, et al. The risk of cataract associated with repeated head and neck CT studies: a nationwide population-based study. AJR Am J Roentgenol. 2013;201(3):626-30. doi: 10.2214/ AJR.12.9652. PubMed PMID: 23971456.

7. Ciarmatori A, Nocetti L, Mistretta G, Zambelli G, Costi T. Reducing absorbed dose to eye lenses in head CT examinations: the effect of bismuth shielding. Australas Phys Eng Sci Med. 2016;39(2):583-9. doi: 10.1007/s13246016-0445-y. PubMed PMID: 27098155.

8. Lopez-Rendon X, Stratis A, Zhang G, Coudyzer $W$, et al. Peak skin and eye lens radiation dose from brain perfusion CT: CTDIvol and Monte Carlo based estimations. Eur J Radiol. 2020;126:108950. doi: 10.1016/j. ejrad.2020.108950. PubMed PMID: 32199141.

9. Wang X, Li G, Zhao J, Song Y, Xiao J, Bai $S$. Verification of eye lens dose in IMRT by MOSFET measurement. Med Dosim. 2019;44(2):107-10. doi: 10.1016/j.meddos.2018.02.015. PubMed PMID: 29678482.

10. Marsh RM, Silosky M. Characterization and implementation of OSL dosimeters for use in evaluating the efficacy of organ-based tube current modulation for CT scans of the face and orbits. Med Phys. 2015;42(4):1730-8. doi: 10.1118/1.4915076. PubMed PMID: 25832062.

11.Zhang D, Li X, Gao Y, Xu XG, Liu B. A method to acquire CT organ dose map using OSL dosimeters and ATOM anthropomorphic phantoms. Med Phys. 2013;40(8):081918. doi: 10.1118/1.4816299. PubMed PMID: 23927332. PubMed PMCID: PMC3739834.

12. Huang Y, Zhuo W, Gao Y, Liu H. Monte Carlo simulation of eye lens dose reduction from CT scan using organ based tube current modulation. Phys Med. 2018;176:72-5. doi: 10.1016/j.ejmp.2018.03.011. PubMed PMID: 
Eye Lens Dose Estimate Based on AAPM 293

29728232. PubMed PMCID: PMC7453996.

13.0ono T, Araki F, Tsuduki S, Kawasaki K. Monte Carlo calculation of patient organ doses from computed tomography. Radiol Phys Technol. 2014;7(1):176-82. doi: 10.1007/s12194-0130250-1. PubMed PMID: 24293361.

14.DeMarco JJ, Cagnon CH, Cody DD, Stevens $\mathrm{DM}$, et al. Estimating radiation doses from multidetector CT using Monte Carlo simulations: Effects of different size voxelized patient models on magnitudes of organ and effective dose. Phys Med Biol. 2007;52(9):2583-97. doi: 10.1088/0031-9155/52/9/017. PubMed PMID: 17440254.

15.Bahadori A, Miglioretti D, Kruger R, Flynn M, et al. Calculation of organ doses for a large number of patients undergoing CT examinations. Am J Roentgenol. 2015;205(4):827-33. doi: 10.2214/AJR.14.14135. PubMed PMID: 26397332. PubMed PMCID: PMC5384467.

16.Zhang D, Cagnon $\mathrm{CH}$, Villablanca JP, McCollough $\mathrm{CH}$, et al. Peak skin and eye lens radiation dose from brain perfusion CT based on Monte Carlo simulation. Am J Roentgenol. 2012;198(2):412-7. doi: 10.2214/ AJR.11.7230. PubMed PMID: 22268186. PubMed PMCID: PMC3918416.

17.Suzuki S, Furui S, Ishitake T, Abe T, Machida $\mathrm{H}$, et al. Lens exposure during brain scans using multidetector row CT scanners: methods for estimation of lens dose. Am J Neuroradiol. 2010;31(5):822-6. doi: 10.3174/ajnr.A1946. PubMed PMID: 20044501. PubMed PMCID: PMC7964184.

18. Andersson J, Pavlicek W, Al-Senan R, Bolch $W$, et al. Estimating Patient Organ Dosewith Computed Tomography: A Review of Present Methodologyand Required DICOM Information. Report No. 246; AAPM; 2019.

19.Boone JM. Reply to "Comment on the 'Report of AAPM TG 204: Size-specific dose estimates (SSDE) in pediatric and adult body CT examinations'" [AAPM Report 204, 2011]. Medical physics. 2012;39(7):46156. doi: 10.1118/1.4725757. PubMed PMID: 28516563. PubMed PMCID: PMC3412437.

20. McCollough C, Bakalyar DM, Bostani M, Brady $S$, et al. Use of water equivalent diameter for calculating patient size and size-specific dose estimates (SSDE) in CT. AAPM Rep. 2014;2014:6-23. PubMed PMID: 27546949.
PubMed PMCID: PMC4991550.

21.Wang J, Duan X, Christner JA, Leng S, Yu $\mathrm{L}$, McCollough $\mathrm{CH}$. Attenuation-based estimation of patient size for the purpose of size specific dose estimation in CT. Part I. Development and validation of methods using the CT image. Med Phys. 2012;39(11):6764-71. doi: 10.1118/1.4754303. PubMed PMID: 23127070.

22. American Association of Physicists in Medicine. Size-specific dose estimate (SSDE) for head CT. AAPM Report No. 293; AAPM; 2019.

23. Khatonabadi M, Kim HJ, Lu P, McMillan KL, et al. The feasibility of a regional CTDIvol to estimate organ dose from tube current modulated CT exams. Med Phys. 2013;40(5):051903. doi: 10.1118/1.4798561. PubMed PMID: 23635273. PubMed PMCID: PMC4108725.

24. Moore BM, Brady SL, Mirro AE, Kaufman RA. Size-specific dose estimate (SSDE) provides a simple method to calculate organ dose for pediatric CT examinations. Med Phys. 2014;41(7):071917. doi: 10.1118/1.4884227. PubMed PMID: 24989395. PubMed PMCID: PMC5148074.

25.Anam C, Haryanto F, Widita R, Arif I, Dougherty $\mathrm{G}$. The profile of size-specific dose estimate (SSDE) along the longitudinal axis in CT using tube current modulation (TCM). Information. 2017;20(1B):377-82.

26. Haba T, Koyama S, Ida Y. Influence of difference in cross-sectional dose profile in a CTDI phantom on X-ray CT dose estimation: a Monte Carlo study. Radiol Phys Technol. 2014;7(1):133-40. doi: 10.1007/s12194-0130242-1. PubMed PMID: 24272457.

27. Anam C, Adhianto D, Sutanto H, Adi K, Ali MH, et al. Comparison of central, peripheral, and weighted size-specific dose in CT. J Xray Sci Technol. 2020;28(4):695-708. doi: 10.3233/ XST-200667. PubMed PMID: 32773401. PubMed PMCID: PMC7505003.

28. Anam C, Haryanto F, Widita R, Arif I, Dougherty $G$, McLean D. Estimation of eye radiation dose during nasopharyngeal CT examination for an individual patient. Information. 2016;19(9B):3951-62.

29. Anam C, Haryanto F, Widita R, Arif I, Dougherty G. Automated calculation of water-equivalent diameter (DW) based on AAPM task group 220. J Appl Clin Med Phys. 2016;17(4):320- 
33. doi: 10.1120/jacmp.v17i4.6171. PubMed PMID: 27455491. PubMed PMCID: PMC5690059.

30.Anam C, Haryanto F, Widita R, Arif I, Dougherty G, McLean D. Volume computed tomography dose index (CTDIvol) and size-specific dose estimate (SSDE) for tube current modulation (TCM) in CT scanning. Int $J$ Radiat Res.
2018;16(3):289-97. doi: 10.18869/acadpub. ijrr.16.3.289.

31. McCollough $\mathrm{CH}$, Leng $\mathrm{S}, \mathrm{Yu} \mathrm{L}$, Cody DD, Boone JM, McNitt-Gray MF. CT dose index and patient dose: they are not the same thing. Radiology. 2011;259(2):311-6. doi: 10.1148/ radiol.11101800. PubMed PMID: 21502387. PubMed PMCID: PMC3079120. 